Cerebrovasc Dis 2012;34:443-445

DOI: $10.1159 / 000344003$

\section{The Appearance of a New White Matter Lesion Adjacent to the Old Infarct in First-Ever Lacunar Stroke Patients: A Two-Year Follow-Up Study with MRI}

\section{Caroline M.J. Loos, Robert J. van Oostenbrugge, Julie Staals}

Department of Neurology, Maastricht University Medical Centre and Cardiovascular Research Institute Maastricht, University Maastricht, Maastricht, The Netherlands

Lacunar infarcts are presumed to be caused by occlusion of a single deep perforating artery [1]. White matter lesions (WMLs) might be caused by chronic hypoperfusion leading to ischemia or blood-brain barrier damage [2,3].

In a follow-up MRI study in lacunar stroke patients, we observed a new WML in the zone adjacent to and just distal (in the vascular territory) from the old infarct in some of the cases. Subsequently, we reviewed all 2-year follow-up scans of our lacunar stroke patient cohort for this particular imaging feature. We describe this imaging feature and discuss a possible mechanism for these WMLs.

\section{Methods}

From a lacunar stroke project we selected all first-ever lacunar stroke patients who had had a baseline brain MRI between 2004 and 2007 and a 2-year follow-up MRI [4]. Lacunar stroke was defined as one of the recognized lacunar stroke syndromes with an acute lacunar infarct on MRI. Patients with potential cardiac embolic sources or carotid stenosis were excluded. Ambulatory 24hour blood pressure monitoring was performed between 1 and 6 months after stroke [4].

MRI (1.5 or 3T) at baseline and 2 years later consisted of standardized axial T2-weighted fast spin echo and FLAIR sequences, with a slice thickness of $5 \mathrm{~mm}$ and gaps of $0.5 \mathrm{~mm}$. An acute lacunar infarct was defined as a T2-weighted hyperintense lesion $(<20 \mathrm{~mm})$ with, if diffusion-weighted imaging (DWI) was performed, restricted diffusion, location in the basal ganglia, internal capsule, thalamus or pons and compatible with clinical findings. We assessed the presence of extensive deep WMLs (Fazekas Scale grade 3) and periventricular WMLs (Fazekas Scale grade 2 or 3). On follow-up MRI, we assessed the presence of a new WML in the zone distal to the old lacunar infarct. We also assessed dif- fuse WML progression, defined as progression in one or more brain areas according to the modified Rotterdam Progression Scale [5], but disregarding the new WML distal to the old lacunar infarct.

Statistical differences between groups were tested using the Student $t$ test for normally distributed variables and the $\chi^{2}$ test for categorical variables.

\section{Results}

Characteristics of 82 patients are shown in table 1 . In 15 cases (18\%), we observed a new WML in the zone distal to the old lacunar infarct. An example is given in figure 1. One of these patients had a transient ischemic attack during follow-up, with clinical symptoms similar to the former lacunar stroke syndrome; none had deterioration of stroke symptoms with poor outcome or a recurrent stroke during follow-up.

Table 1. Clinical and imaging characteristics

\begin{tabular}{|c|c|c|c|c|}
\hline & \multirow{2}{*}{$\begin{array}{l}\text { Total } \\
(\mathrm{n}=82)\end{array}$} & \multicolumn{2}{|c|}{ New WML } & \multirow{2}{*}{$\begin{array}{l}\mathrm{p} \\
\text { val- } \\
\text { ue }\end{array}$} \\
\hline & & $\begin{array}{l}\text { absent } \\
(\mathrm{n}=67)\end{array}$ & $\begin{array}{l}\text { present } \\
(\mathrm{n}=15)\end{array}$ & \\
\hline \multicolumn{5}{|l|}{ Demographics at baseline } \\
\hline Age at stroke onset, years & $63 \pm 11$ & $62 \pm 11$ & $65 \pm 12$ & 0.38 \\
\hline Male & $48(58)$ & $40(60)$ & $8(53)$ & 0.6 \\
\hline Hypertension & $60(73)$ & $49(73)$ & $11(73)$ & 0.9 \\
\hline Diabetes & $13(16)$ & $12(18)$ & $1(7)$ & 0.28 \\
\hline Hypercholesterolemia & $65(79)$ & $54(81)$ & $11(73)$ & 0.53 \\
\hline Smoking & $33(40)$ & $27(40)$ & $6(40)$ & 0.59 \\
\hline
\end{tabular}

\section{Blood pressure at baseline, $\mathrm{mm} \mathrm{Hg}$}

24 h systolic $\quad 140 \pm 17 \quad 140 \pm 17 \quad 135 \pm 18 \quad 0.18$

$\begin{array}{lllll}24 \mathrm{~h} \text { diastolic } & 84 \pm 11 & 84 \pm 11 & 75 \pm 9 & 0.00\end{array}$

24 h MAP $\quad 107 \pm 12107 \pm 12100 \pm 11 \quad 0.03$

MRI at baseline

Extensive periventricular

$\begin{array}{lllll}\text { WML } & 31(38) & 25(37) & 6(40) & 0.85\end{array}$

$\begin{array}{lllll}\text { Extensive deep WML } & 28(34) & 23(34) & 5(34) & 0.94\end{array}$

\begin{tabular}{lllll}
\hline MRI at follow-up & & & & \\
Progression of diffuse WML & $40(49)$ & $31(46)$ & $9(60)$ & 0.37 \\
\hline
\end{tabular}

Numbers $(\%)$ or means \pm standard deviation. MAP $=$ Mean arterial pressure.

\section{KARGER}

Fax +41613061234 E-Mail karger@karger.ch www.karger.com

\section{(c) 2012 S. Karger AG, Basel}

$1015-9770 / 12 / 0346-0443 \$ 38.00 / 0$

Accessible online at:

www.karger.com/ced
C.M.J. Loos

Department of Neurology, MUMC

PO Box 5800

NL-6202 AZ Maastricht (The Netherlands)

E-Mail c.loos@mumc.nl 

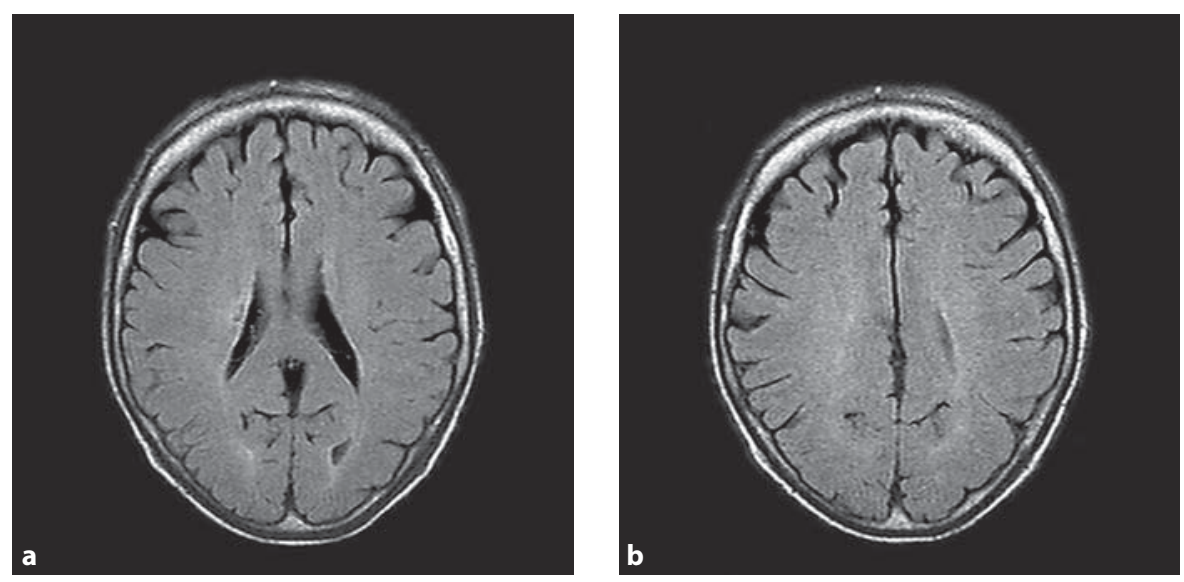

Fig. 1. FLAIR-images. a A right-sided periventricular symptomatic lacunar infarct at baseline (MR was performed 94 days after stroke onset). b MRI-slice distal (cranial) to the lacunar infarct at baseline. c Lacunar infarct after 2-year follow-up imaging. d Although scan levels do not completely correspond between baseline and followup imaging, a new WML can be seen just distal to the old infarct.
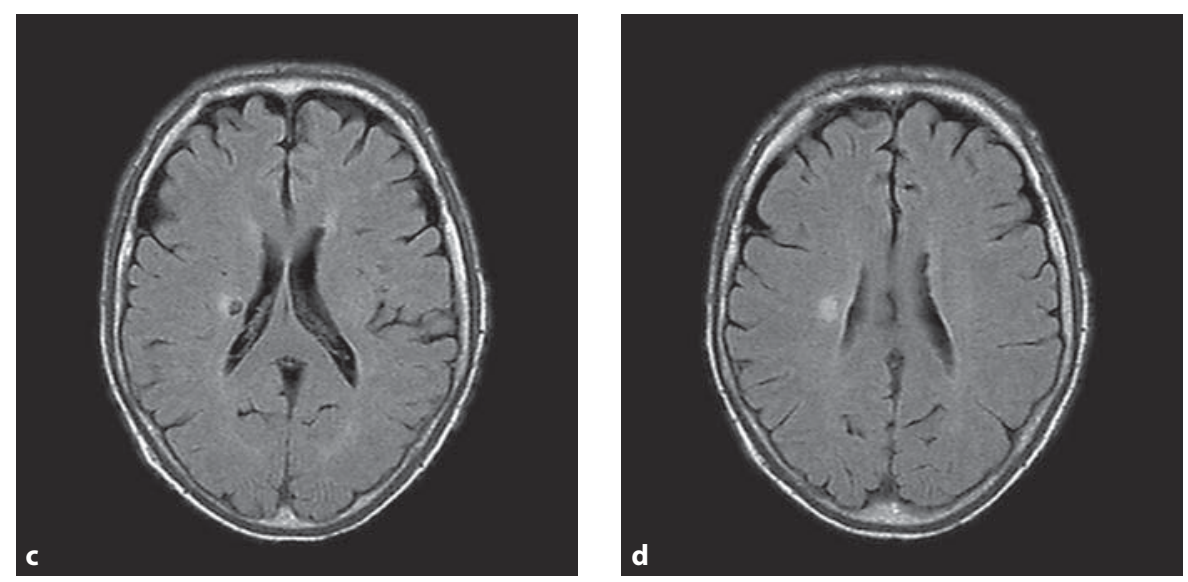

These new WMLs were single and mostly round with indistinct margins, but could be clearly outlined from diffuse WMLs (if present), with a mean diameter of $13 \pm 2 \mathrm{~mm}$. They were all located adjacent to and just distal from the lacunar infarct in the vascular territory of the deep perforators. Ten of 15 patients with a new WML had DWI at baseline and at follow-up. However, none of these new WMLs showed restricted diffusion at follow-up. The occurrence of these WMLs was not associated with vascular risk factors or the presence of extensive diffuse WMLs at baseline or progression of WMLs at follow-up. Mean diastolic and mean arterial blood pressures at baseline were significantly lower in the group with a new WML (table 1).

\section{Discussion}

We have described our observation of a new WML in the zone just adjacent to the old lacunar infarct after 2 years of follow-up in first-ever lacunar stroke patients. While endothelial dysfunction and altered permeability of the blood-brain barrier are thought to be involved in the pathogenesis of diffuse WMLs $[3,6]$, we speculate that these particular new distal zone WMLs have a different pathogenesis. Considering their localization (always distal to the lacunar infarct and clearly outlined from diffuse WMLs) and occurrence, independently of overall WML progression, these lesions might be the consequence of chronic hypoperfusion in the internal border zone at the end of the vascular territory of deep perforators. As one side of the internal border zone is locally struck by occlusion of a deep perforator, resulting in a lacunar infarct, this zone might become more vulnerable for reduction in perfusion pressure and chronic ischemia, resulting in a WML. Cerebral small vessel disease has indeed been described as a frequent cause of internal border-zone ischemia, due to impaired vascular autoregulation [7]. Furthermore, patients with this particular WML had lower diastolic and mean arterial blood pressures, which compromises perfusion pressure. However, it should be noticed that blood pressure was measured at baseline only.

An important limitation is that we did not use the same MRI field strength in all patients. Two patients with a new WML had 1.5-T MRI at baseline and 3-T MRI at follow-up, which might have led to increased detection instead of a 'real' new WML. However, a recent review stated that there is no objective evidence of increased lesion detection at 3-T MRI than at 1.5-T MRI [8]. Furthermore, all other patients with a new WML had an MRI with equal or lower field strength at follow-up. Another limitation is that not all patients had DWI at baseline; therefore, we cannot exclude that in some patients the original ischemic zone was larger at the acute onset. However, these new WMLs were always distal from the original infarct, not surrounding it, and were never seen at baseline MR imaging; therefore, it seems un- 
likely that the new WML was just a part of the original lacunar ischemic zone. Larger prospective studies are necessary to confirm our observation and the relation with arterial blood pressure measurements.

\section{Disclosure Statement}

C.M.J.L. was supported by the Dutch Pearl String Initiative.

\section{References}

1 Fisher CM: Lacunar strokes and infarcts: a review. Stroke 1982;32:871876.

2 Pantoni L: Cerebrall smell vessel disease: from pathogenesis and clinical characteristics to therapeutic challenges. Lancet Neurol 2010;9: 689-701.

3 Wardlaw JM, Sandercock PAG, Dennis MS, Starr J: Is breakdown of the blood-brain barrier responsible for lacunar stroke, leukoaraiosis, and dementia? Stroke 2003;34:806-812.
-4 Staals J, van Oostenbrugge RJ, Knottnerus ILH, Rouhl RPW, Henkens LHG, Lodder J: Brain microbleeds relate to higher ambulatory blood pressure levels in first-ever lacunar stroke patients. Stroke 2009;40: 3264-3268.

5 Gouw AA, van der Flier WM, van Straaten ECW, Pantoni L, BastosLeite AJ, Inzitari D, et al: Reliability and sensitivity of visual scales versus volumetry for evaluating white matter hyperintensity progression. Cerebrovasc Dis 2008;25:247-253.

-6 Knottnerus IL, Ten Cate H, Lodder J, Kessels F, van Oostenbrugge RJ: Endothelial dysfunction in lacunar stroke: a systematic review. Cerebrovasc Dis 2009;27:519-526.

-7 Immink RV, van Montfrans GA, Stam J, Karemaker JM, Diamant M, van Lieshout JJ: Dynamic cerebral autoregulation in acute lacunar stroke and middle cerebral artery territory ischemic stroke. Stroke 2005;36:2595-2600.

8 Wardlaw JM, Brindle W, Casado AM, Shuler K, Henderson M, Thomas B, et al: A systematic review of the utility of 1.5 versus 3 Tesla magnetic resonance brain imaging in clinical practice and research. Eur Radiol 2012;22:2295-2303. 